\title{
Lists \& More Lists: Making Sense Of Corporate Reputations
}

Kathleen Campbell, Saint Joseph's University, USA

W. Richard Sherman, Saint Joseph's University, USA

\begin{abstract}
What would you like to know about a company? What value has the company created in the past, is creating currently, and will create in the future? The creation of financial value is not only important; it is necessary - but is it enough? This study explores the relationships between and among lists of top performers - Boston College's Corporate Social Responsibility Index, Fortune's World's Most Admired Companies, Harris Interactive's Reputation Quotient for the Most Visible Companies, and Newsweek's Green Rankings of America's 500 largest corporations. Its objective is to see whether in spite of differing methodologies and criteria for rankings, there is a commonality of inclusion in lists. In effect, this paper attempts use statistical analysis in order to determine if there is an agreement as to which companies are top corporate citizens in the United States.
\end{abstract}

Keywords: Corporate Social Responsibility, Corporate Reputation

\section{INTRODUCTION}

$\mathcal{J}$

oday we are in the midst of a rapid global transformation with increased demand on corporations to perform not only financially but to be good corporate citizens. One of the most important aspects of this transformation is the critical importance of Corporate Social Responsibility (CSR) programs. Climate change; community health, education and development; and business sustainability are some of the most pressing issues of our time. Businesses are increasingly involved in these areas as are their clients and their people. This raises the importance of accurately and transparently accounting for and reporting these activities. Lord Michael Hastings, Global Head of Citizenship \& Diversity, KPMG International (KPMG, 2008, p. 2).

Financial success has long been accepted as the primary objective of corporate existence. However, many social critics have questioned whether financial success is enough. There are increasing demands that companies be good corporate citizens as well. Organizations struggle to tell their stories, to communicate the good (and sometimes the bad) that they do in the marketplace, in the community, to and for the environment, and in society. Quite clearly, the challenge of telling the company's story is not being met by current corporate reporting practices. In particular, criticism has been directed at the failure of annual reports or other regulatory files to tell anything about a company's environmental and social performance. Triple bottom-line (TBL) reporting, a term coined by John Elkington in his 1997 book Cannibals with Forks: the Triple Bottom Line of 21st Century Business, aims to remedy this shortcoming by explicitly considering not only the economic performance of a firm but also the company's environmental and social performance as well. An increasingly popular practice is the issuance of a corporate responsibility or sustainability report. The international accounting firm KMPG reviewed the disclosures of more than 2,200 companies, including the Global Fortune 250 and 100 largest companies in 22 countries. The KPMG International Survey on Corporate Responsibility Reporting (2008) found that 74 percent of the top 100 U.S. companies (as measured by revenue) published corporate responsibility information in 2008, either as part of their annual financial report or as a separate document. This was an increase from the 37 percent of top U.S. companies that KPMG surveyed in 2005. An even higher percentage of top international firms are reporting on their environmental and social performance with 80 percent of the Global Fortune 250 companies now releasing this information. 
Despite the impressive increase in the reports being issued, there is a continuing general dissatisfaction with the information contained in these reports. In a 2008 survey of 2,279 respondents worldwide, 452 did not read sustainability reports because they thought there were better ways to get information about a company's environmental and social performance (KPMG \& SustainAbility, 2008). In this same survey, 25\% of the respondents felt that the most significant issues were entirely absent from the reports with a slight majority feeling the most significant issues weren't treated with enough detail. Those who participated in the survey felt the most significant omission in sustainability reports was the absence of any acknowledgement of the company's failures.

The lapses and lagging of information in corporate disclosures may be the reason people look to other sources to form an opinion of how a company is fulfilling its obligations to other stakeholders. There seem to be no shortage of these other sources. Lists and rankings of companies in respect to their non-financial performances abound. This study explores the relationships between and among some of these lists of top performers - Boston College's Corporate Social Responsibility Index, Fortune's World's Most Admired Companies, Harris Interactive's Reputation Quotient for the Most Visible Companies, and Newsweek's Green Rankings of America's 500 largest corporations. Its objective is to see whether in spite of differing methodologies and criteria for rankings, there is a commonality of inclusion in lists. In effect, this paper attempts use statistical analysis in order to determine if there is an agreement as to which companies are top corporate citizens in the United States.

\section{THE LISTS}

\section{Boston College's Corporate Social Responsibility Index}

Based on data collected by Boston College's Reputation Institute, rankings of companies according to a Corporate Social Responsibility Index (hereinafter CSRI) were first released in 2008. The underlying assumption of the CSRI is a company's reputation is closely linked to the perception of its corporate responsibility. In essence, the survey from which the data for the CSRI is derived focuses the public perception of how a company treats employees, the company's ethics, the company's community involvement and the company's respect for the environment. Score range from 0 to 100, with a mean of 64.2 for the companies rated in 2008. Each score is the average of perceptions along for dimensions - trust, esteem, admiration and good feeling (Reputation Institute, 2009).

The top 50 companies as ranked by CSRI can be found in Appendix B.

\section{Fortune's World's Most Admired Companies}

Fortune's list of Most Admired Companies (hereinafter Fortune) has the longest standing among the four lists examined. Fortune's first ranking was released in 1997. Partnering with the Hay group, Fortune surveys 15,000 top executives, outside directors, and financial analysts in order to find companies with the strongest reputation within their industry and across all industries (Fortune, 2009). Much broader in the scope of its criteria, the Most Admired Companies lists looks at the following nine attributes: ability to attract and retain talented people; quality of management; social responsibility to the community and the environment; innovativeness; quality of products or services; wise use of corporate assets; financial soundness; long-term investment value; and effectiveness in doing business globally (Hay Group, 2009).

For each attribute, the respondent is asked to rate the company on 10 point scale, with 1 being "poor" and 10 being "excellent." The final rankings, within 64 separate industries, are based on the companies' "corporate reputation score" which is the simple average of the attribute scores. To become "most admired," a company's corporate reputation score must rank in the top 50\% in its industry. The overall ranking of most admired companies is developed through a separate procedure. Last year, 4,047 respondents were asked to identify the top 10 companies they admire most, regardless of industry, from a list that contains the top $25 \%$ from the previous year's overall survey and the top $20 \%$ of this year's industry surveys (Hay Group, 2009).

In 2009 Fortune combined the America's Most Admired Company survey with the World's Most Admired Company. The top 50 companies as ranked by Fortune can be found in Appendix C. 


\section{Harris Interactive's Reputation Quotient}

Harris Interactive has been calculating its Reputation Quotient (hereinafter $R Q$ ) for 10 years. Surveying more than 25,000 US consumers, Harris first asked its respondents to identify the 60 "most visible" companies. Once the most visible companies are identified, the respondents rank the companies with respect to their reputation in six categories: Emotional Appeal, Products \& Services, Social Responsibility, Vision \& Leadership, Workplace Environment, and Financial Performance. For its latest rankings, the identification of most visible companies was conducted from September to October 2008. The second phase (i.e., rating of reputations) was conducted from December 31, 2008 to February 2, 2009 (Harris, 2009).

The top 50 companies as ranked by Harris can be found in Appendix D.

\section{Newsweek's Green Rankings}

In September 2009, Newsweek released its first ranking of companies based on the environmental performance. In order to arrive at its rankings of the largest 500 US companies (as measured by revenue, market capitalization, and number of employees), Newsweek partnered with KLD Research \& Analytics, Trucost, and CorporateRegister.com, to calculate a "Green Score" for each company based on the total costs of their environmental impact, their corporate environmental policies and performance, and their reputation based on an opinion survey of more than 13,000 users of the CorporateRegister.com website and of executives of the 500 largest US companies (Schwartz, 2009).

While KLD Research, Trucost and CorporateRegister.com all used separate methodologies, their results were standardized by conversion into Z-scores. The resulting "Green Score" is the weighted sum of the three component Z-scores. Environmental impact and corporate environment policy scores each received a weighting of 45 percent. The remaining $10 \%$ was allocated to the company's reputation. An additional factor in the rankings is a company's greenhouse gas (GHG) emissions (Newsweek, 2009).

The top 50 companies as ranked by Newsweek can be found in Appendix E.

\section{METHODOLOGY}

In order to ensure that the comparisons of the four separate rankings are as similar as possible, the focus was only on the top 50 companies from each list. As noted previously, the top 50 on each list can be found in Appendices B through E. Within these lists a comparison of pairs allows for six separate analyses and gives one the ability to look closely for any distinct relationship. While there were many companies that were on the more than one list, it is critical to note that none of the lists were a direct comparison of the same 50 companies. Because of this, the non-parametric measure of correlation used, Spearman's rank correlation coefficient (i.e., Spearman's Rho), as well as the non-parametric used to measure the degrees of correspondence between the two rankings and the significance of this correspondence, Kendall's Tau correlation coefficient, are useful but not entirely statistically valid, reliable, or ethical.

The calculation of Spearman's Rho allows for a quick overview about whether or not a direct relationship between the rankings is evident. Since very little, if any, information is given about how the rankings were created, one must wonder how much validity to attach to the order of the ranking as well as the overall ranking itself of each list. Because there is no separation of classification of industries (e.g. automotive, technology, retail), it is hard to assess whether the industry itself plays a factor in the overall ranking. Without knowing what factors are being used, one might wonder if there are any similarities at all. Spearman's Rho helps shed some light on the feasibility that the rankings were done using very similar or very different methodologies.

The calculation of Kendall's Tau allows one to state whether or not in reality there is a significant relationship between these rankings in such a way that one could claim that there is evidence that the same factors were taken into consideration. The combination of the Spearman's Rho and Kendall's Tau allows for reasonable conclusions to be drawn. The output and graphs that follow in Appendix A, Tables 1 through 6, help to show the 
relationships, or lack thereof, from the six comparisons that are being made. Appendix F lists the seven companies that made it into all four top fifty lists, along with where they were ranked in each.

\section{ANALYSIS}

As a first step, Boston College's Corporate Social Responsibility Index (CSRI) is compared to the other three rankings. When comparing CSRI to the Fortune's World's Most Admired Companies (Fortune), it can be seen that two lists have 27 companies in common. Despite this commonality of companies, the Spearman's Rho of .332 is indicative of a minimal chance that similar factors were used to create the ranking. At a 5\% level of significance, the p-value of.0839 offers further support to the conclusion that there is no evidence that there are similar factors. However, the fact that the p-value is relatively low and these two lists do share more than $50 \%$ of the same companies leads one to believe that they do indeed have some similar factors. Therefore, before making an absolute statement, further analysis should be done. Looking at Appendix A, Table 1, the scattered points give further evidence of a lack of a relationship between CSRI and Fortune's ranking.

Next, when comparing CSRI to Newsweek's Green Ranking (hereinafter Newsweek), it can be seen that the two lists share only 14 of the same companies. With this small sample, the Spearman's Rho of -.284 is very small and indicates that it is very unlikely original criteria used for the ranking are in any way similar. At a $5 \%$ level of significance, the p-value of.3046 supports the same conclusion that there is no evidence that the CSRI and Newsweek had any similar factors in creating their rankings of sustainability. Finally, looking at the first scatterplot in Appendix A, Table 2, the scattered points lend further support for the conclusion that there is a lack of a relationship.

The comparison of CSRI to Harris Interactive's Reputation Quotient (RQ) provides overwhelming evidence that the two lists had some similar foundations in their effort to rank. Not only do the two ranking share 19 companies, the Spearman's Rho of .759 indicates a decent relationship. Likewise, using a 5\% level of significance, the p-value of .000103 gives further evidence that some similar factors were used to create the these two rankings. This is further supported by the graph in Appendix A, Table 3. This scatterplot shows that there is a string relationship between these two rankings.

As a second step the relationships between Fortune and to the two remaining rankings, Newsweek and $R Q$, is examined. Looking at Fortune in comparison to Newsweek, there are only 16 companies in common. Both the sample size and any common factors being used by the two types of ranking are questionable. Furthermore, with a Spearman's Rho of .086, there is clear evidence that there were no similar factors taken into consideration when creating each ranking. Similarly, at a 5\% level of significance, the p-value of .7434 is evidence that there are no apparent shared factors when creating these rankings. Finally, looking at Appendix A, Table 4, the scatterplot in the graph shows sporadic points indicating that no relationship exits.

When comparing Fortune to $R Q$, there seems to be conflicting results. In part, this may be due to the large number of shared companies in their lists. In this case, there were 31 common companies listed in the two rankings. The relatively low Spearman's Rho (.385) implies that there are no commonalities in the rankings by the two groups. However, the p-value was .0298 , which at a significance level of 5\% indicates that there is indeed a relationship between the factors involved in creating the ranking. Looking at Appendix A, Table 5, one can see how a linear relationship might be observed while some very influential observations seem to be working against the slope. Therefore, the graph is consistent with the small value for the Spearman's Rho but leaving open the question of whether a significant relationship might still exist. It would be imperative to do further analysis before drawing an absolute conclusion regarding these two ranking systems.

As a final analysis, when comparing Newsweek with $R Q$, there are again very strong negative results, despite the fact that the two rankings had 28 companies in common. In fact, the Spearman's Rho is -.010. This extremely low value (i.e., almost 0) indicates there are no similar factors at all between these two rankings. Likewise, when comparing to a $5 \%$ level of significance, the p-value is found to be .9574 which is again absolute evidence that there are no common factors. It should be noted that this result is surprising because of the fifty possible companies, the two lists share more than $50 \%$ of them and this would seem to imply that some similar 
features about the companies were used. However, as seen by the lack of any linear pattern in Appendix A, Table 6, the rankings of these 28 companies are extremely different.

\section{CONCLUSION}

Because accounting and other forms of corporate disclosures have seemingly failed to provide an adequate basis for evaluating the non-financial performance of a company, it is not at all surprising that other forms of ranking the best performing corporate citizens have attempted to fill the void. This study has looked at four of these ranking schemes in order to determine whether there is a common denominator between and among the lists.

Overall, the data provided the conclusion that Boston College's Corporate Social Responsibility Index (CSRI) and Harris Interactive's Reputation Quotient $(R Q)$ have a very strong likelihood that the parameters chosen to make their rankings have evident similarities. Although the rankings shared $38 \%$ of the same companies, there is statistical significance when looking at how similarly they were ordered for these rankings. Meanwhile Newsweek's Green Rankings show no evidence that any of the factors that it uses could relate to any of the other rankings. This is indicative that the parameters chosen to create the ordering for the ranking held no relationship with any other company making one continue to question how the order was created and if the order has any real value.

The other oddity in the findings relates to Fortune's World's Most Admired Companies. This set of rankings sticks out as being very different that the others despite having so many shared companies. Fortune shares $54 \%$ of their companies commonly with CSRI and 62\% of their companies are shared with $R Q$. Yet, the Spearman's Rho for each individual comparison shows that the rankings of these are very different. Therefore, with further analysis, one might be able to identify a confounding variable that connects the three. On the other hand, the significance, and almost significant, p-values could simply have occurred because of the larger shared sample sizes. Without knowledge of how the rankings were created, both of these possibilities are equally valid.

\section{LIMITATIONS}

The first major limitation to the data is that there are not many known facts about the parameters used to initially create the lists. The discussion from each organization creating the lists is vague and confusing. The specific formulas or statistical tests used are not disclosed. Although the need to differentiate the companies being ranked by size and/or industry was given is referenced multiple times, none of the four list refer or discuss this differentiation. Also, it is not evident what the initial populations were from which the lists were drawn. Had this been disclosed, one could better determine if it would even be possible to have all of the same companies on two separate lists. Overall, if more information could be found from within the organizations that release the surveys, the comparisons might be more valid.

Second, after much research on current methodologies when looking at order statistics, it quickly becomes evident that there is not really an accepted metric or known formula to evaluate qualitative data that matches directly. Because this data has quite a few shared observations, typically over $40 \%$, it would seem that there should be a way to analyze the different ordering. However, no robust method has yet been found. Therefore, in creating this output using the Spearman's Rho and Kendall's Tau, one might find feasible significance but lack both power and absolute assurance that the significance holds.

\section{FUTURE RESEARCH}

Upon realizing the limitations of current methodologies for comparing lists of qualitative data, it becomes apparent that this is an area of research that needs further investigation. Therefore, the focus of future research will be aimed at narrowing down a powerful and robust method of evaluating listings for comparison when not all of the elements match. 


\section{AUTHOR INFORMATION}

Kathleen Campbell is a Visiting Instructor of Decision Sciences at the Saint Joseph's University's Haub School of Business in Philadelphia, Pennsylvania, USA. Katie majored in Business as an undergraduate at Drexel, earned a Master's degree in Applied Statistics from Villanova, and is currently working on achieving a $\mathrm{PhD}$ in Statistics from Temple University. Katie has been the recipient of awards for teaching excellence. She is planning on completing her PhD with research in Order Statistics by the Spring of 2012.

W. Richard Sherman is a Professor of Accounting at the Saint Joseph's University's Haub School of Business in Philadelphia, Pennsylvania, USA. After majoring in Sociology as an undergraduate, Rick earned his law degree, an MBA with a concentration in Accounting, and a graduate degree in tax law. Recipient of numerous awards for teaching excellence, including the prestigious Lindback Foundation Award for Distinguished Teaching, Professor Sherman has published over 50 articles in academic and professional journals. His research spans issues in accounting education, tax, uses of accounting information, and sustainability/Triple Bottom Line reporting.

\section{REFERENCES}

1. Elkington, J. (1997). Cannibals with forks: the triple bottom line of the $21^{\text {st }}$ century business. Capstone, Oxford.

2. $\quad$ Fortune (2009). World's most admired companies. Accessed 23 March 2010 at http://money.cnn.com/magazines/fortune/mostadmired/2009/index.html

3. Hay Group (2009). Fortune's world's most admired companies: How we identify and rank the most admired. Accessed on 23 March 2010 at http://www.haygroup.com/ww/Best_Companies/Index.aspx?ID=1582.

4. KPMG (2008). International survey of corporate responsibility reporting 2008. Accessed on 23 March 2010 at http://www.kpmg.com/Global/en/IssuesAndInsights/ArticlesPublications/Documents/Internationalcorporate-responsibility-survey-2008.pdf

5. KPMG \& SustainAbility (2008). Count me in: the reader's take on sustainability reporting. Accessed on 23 March 2010 at http://www.globalreporting.org/NR/rdonlyres/3F57ACC8-60D0-48F0-AF28527F85A2A4B4/0/CountMeIn.pdf.

6. Newsweek (2009). Green rankings methodology. Accessed on 23 March 2010 at http://www.newsweek.com/id/215522.

7. Reputation Institute (2009). Google, Campbell Soup, J\&J top in CSR. Accessed 23 March 2010 at http://www.marketingcharts.com/topics/branding/google-campbell-soup-jj-tops-in-csr-6760/.

8. Schwartz, A. (2009). How accurate are Newsweek's green company rankings? Accessed 23 March 2010 at http://www.fastcompany.com/blog/ariel-schwartz/sustainability/how-accurate-are-newsweeks-greencompany-rankings. 


\section{APPENDIX A}

Table 1: Comparison of CSRI and Fortune

Spearman's Rho $=.332 ; \mathrm{p}$-value $=.0839$. No relationship but interesting results.

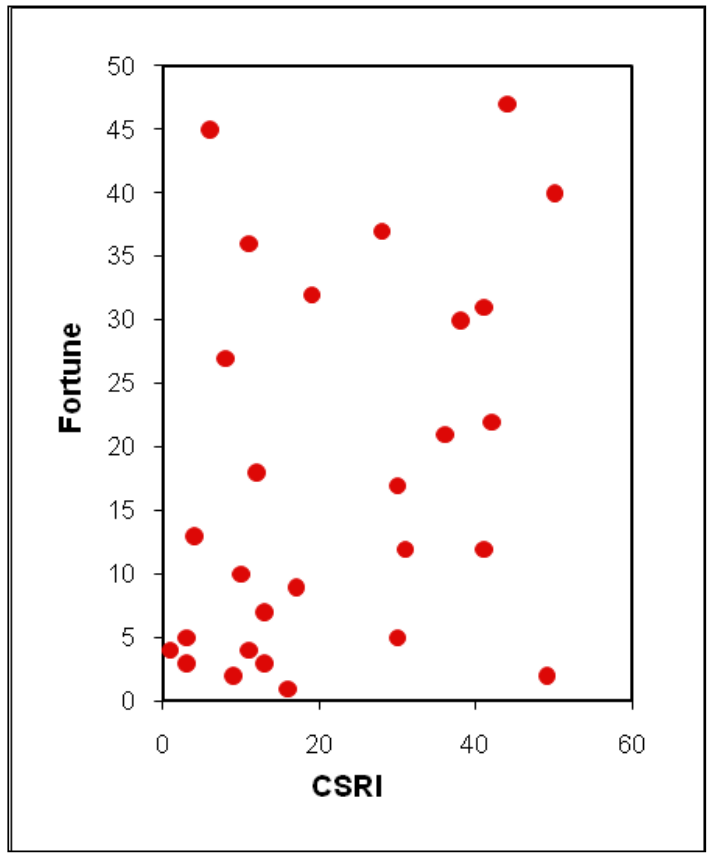

Table 2: Comparison of CSRI and Newsweek

Spearman's Rho $=-.284 ;$ p-value $=.3046$. No real relationship found.

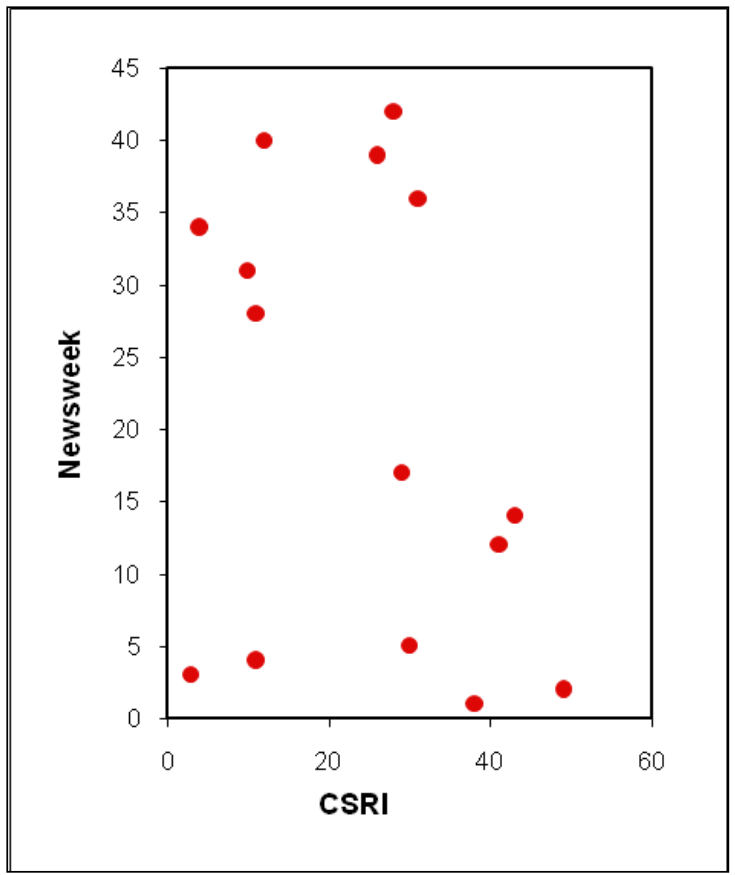


Table 3: Comparison of CSRI and RQ

Spearman's Rho $=.759 ; \mathrm{p}$-value $=.000103$. Evident relationship found .

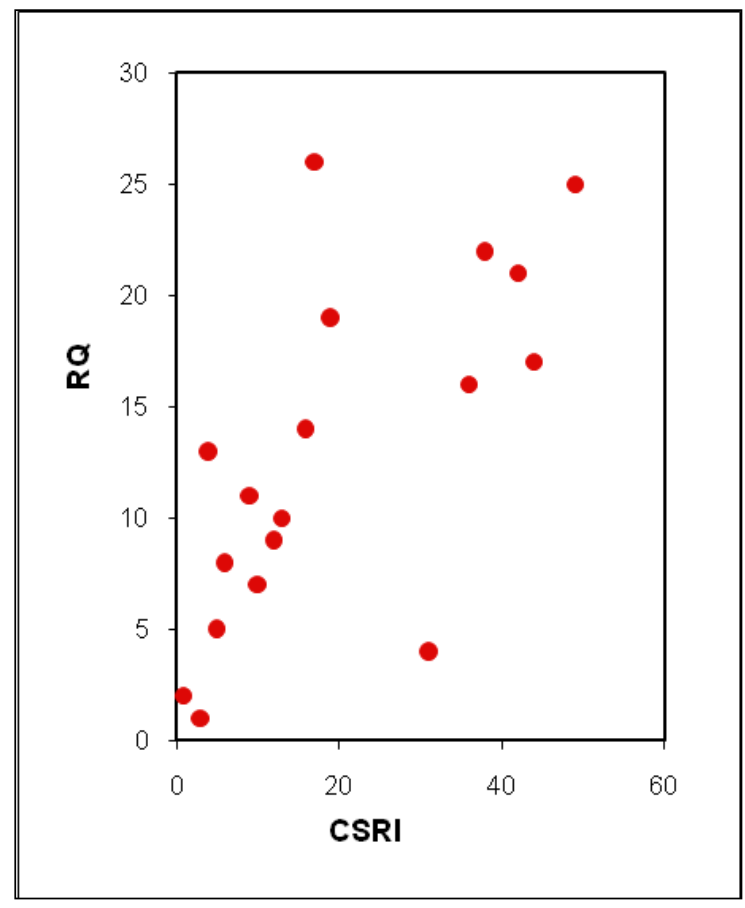

Table 4: Comparison of Fortune and Newsweek Spearman's Rho $=-.086$; $\mathrm{p}$-value $=.7434$. No relationship.

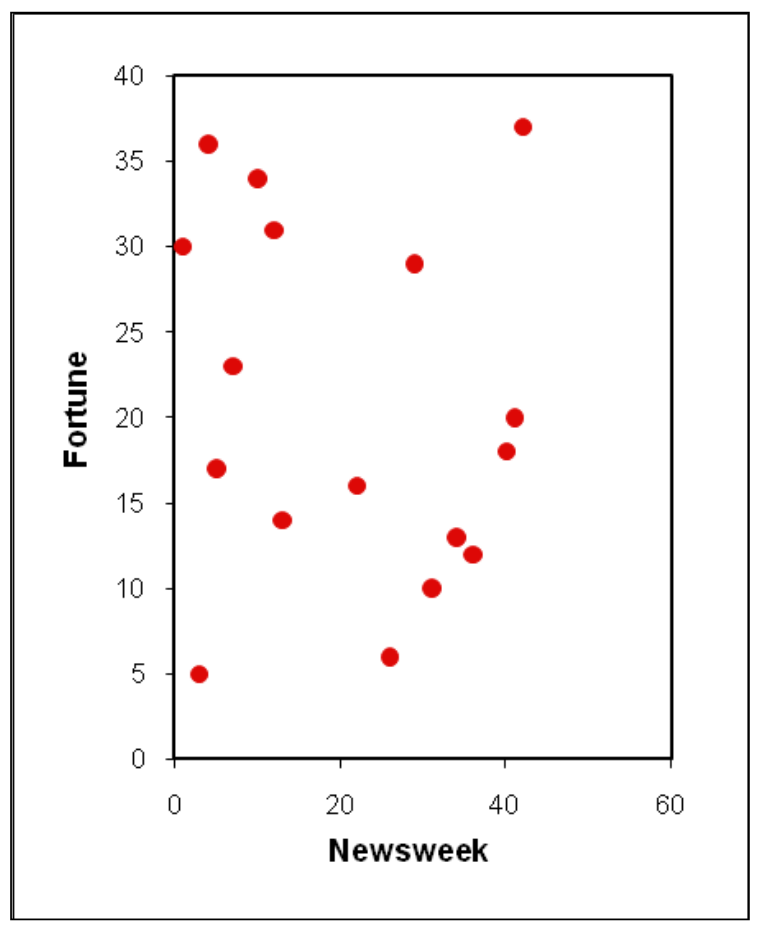


Table 5: Comparison of Fortune and $R Q$

Spearman's Rho $=.385 ; \mathrm{p}$-value $=.0298$. This too supplies some interesting results.

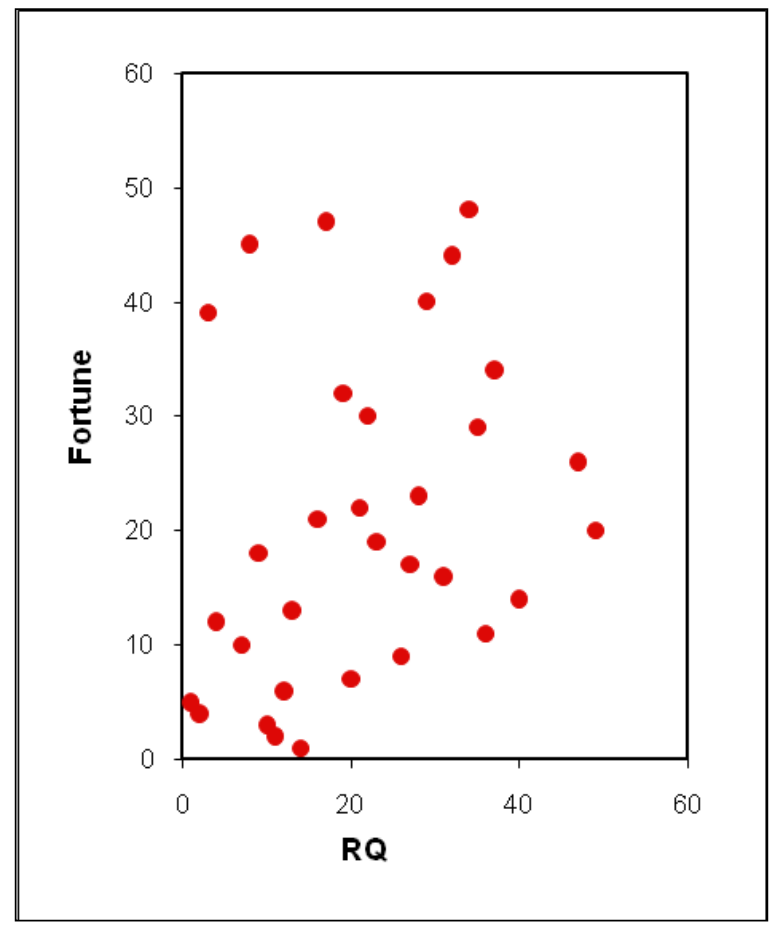

Table 6: Comparison of Newsweek and $R Q$

Spearman's Rho $=-.010$ : $\mathrm{p}$-value $=.9574$. No relationship.

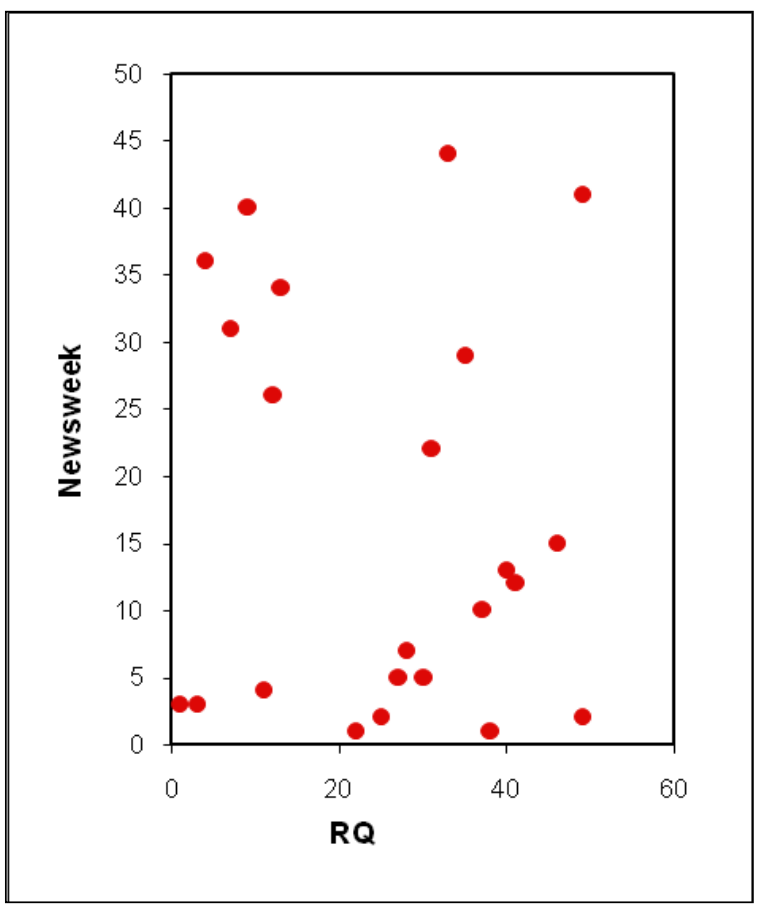


APPENDIX B

Top 50 for Boston College's Corporate Social Responsibility Index

\begin{tabular}{|c|c|c|c|c|c|c|c|}
\hline Rank & Company Names & Rank & Company Names & Rank & Company Names & Rank & Company Names \\
\hline 1 & Google & 14 & Anheuser-Busch & 27 & Green Mountain Coffee Roaster & 40 & Eastman Kodak \\
\hline 2 & Campbell Soup & 15 & Sara Lee & 28 & Marriott International & 41 & Cisco Systems \\
\hline 3 & $\mathbf{J} \& \mathbf{J}$ & 16 & Apple & 29 & Advanced Micro Devices & 42 & Costco Wholesale \\
\hline 4 & Walt Disney & 17 & General Electric & 30 & IBM & 43 & Sun Microsystems \\
\hline 5 & Kraft Foods Inc. & 18 & Publix Markets & 31 & The Coca-Cola Company & 44 & Loews Cos. \\
\hline 6 & General Mills & 19 & Honda of America & 32 & Whirlpool Corporation & 45 & Walgreens \\
\hline 7 & Levi Strauss \& Co. & 20 & Deere \& Company & 33 & Aflac & 46 & Fidelity Inv. \\
\hline 8 & UPS & 21 & Adobe Systems & 34 & Office Depot & 47 & Express Scripts \\
\hline 9 & Berkshire Hathaway & 22 & Xerox & 35 & TIAA-CREF & 48 & Deloitte \& Touche \\
\hline 10 & Microsoft & 23 & New Balance & 36 & PepsiCo & 49 & Dell \\
\hline 11 & Intel & 24 & Toyota Motor Corp. & 37 & Nokia & 50 & Boeing \\
\hline 12 & $3 \mathrm{M}$ & 25 & Texas Instruments & 38 & Timberland Company & & \\
\hline 13 & FedEx & 26 & Colgate-Palmolove & 39 & Eastman Kodak & & \\
\hline
\end{tabular}

\section{APPENDIX C}

Top 50 for Fortune's Most Admired Companies

\begin{tabular}{|c|c|c|c|c|c|c|c|}
\hline Rank & Company Names & Rank & Company Names & Rank & Company Names & Rank & Company Names \\
\hline 1 & Apple & 14 & Wells Fargo & 27 & UPS & 40 & Boeing \\
\hline 2 & Berkshire Hathaway & 15 & Goldman Sachs & 28 & BMW & 41 & Deere \\
\hline 3 & Toyota Motor & 16 & McDonald's & 29 & American Express & 42 & Nokia \\
\hline 4 & Google & 17 & IBM & 30 & Hewlett-Packard & 43 & Northwestern Mutual \\
\hline 5 & Johnson \& Johnson & 18 & $3 \mathrm{M}$ & 31 & Cisco Systems & 44 & Best Buy \\
\hline 6 & Proctor \& Gamble & 19 & Target & 32 & Honda Motor & 45 & General Mills \\
\hline 7 & FedEx & 20 & J. P. Morgan Chase & 33 & Singapore Airlines & 46 & Toyota Industries \\
\hline 7 & Southwest Airlines & 21 & PepsiCo & 34 & Starbucks & 47 & Lowe's \\
\hline 9 & General Electric & 22 & Costco Wholesale & 35 & Caterpillar & 48 & AT\&T \\
\hline 10 & Microsoft & 23 & Nike & 36 & Intel & 49 & Accenture \\
\hline 11 & Wal-Mart Stores & 24 & Nordstrom & 37 & Marriott Int'l & 50 & Samsung Electronics \\
\hline 12 & Coca-Cola & 25 & Exxon Mobil & 38 & Nestle & & \\
\hline 13 & Walt Disney & 26 & Bank of America & 39 & Sony & & \\
\hline
\end{tabular}


APPENDIX D

Top 50 for Harris Interactive's Reputation Quotient

\begin{tabular}{|c|c|c|c|c|c|c|c|}
\hline Rank & Company Names & Rank & Company Names & Rank & Company Names & Rank & Company Names \\
\hline 1 & $\mathrm{~J} \& \mathrm{~J}$ & 14 & Apple & 27 & IBM & 40 & Wells Fargo \\
\hline 2 & Google & 15 & Unilever & 28 & Nike & 41 & $\mathrm{BP}$ \\
\hline 3 & Sony & 16 & Pepsico & 29 & Boeing & 42 & AllState \\
\hline 4 & Coca-Cola & 17 & Lowes & 30 & Verizon & 43 & Sear Holdings \\
\hline 5 & Kraft Foods Inc. & 18 & Whole Foods & 31 & McDonald's & 44 & Chevron \\
\hline 6 & Amazon & 19 & Honda & 32 & Best Buy & 45 & Time Warner \\
\hline 7 & Microsoft & 20 & Southwest Airlines & 33 & J. C. Penney & 46 & Sprint \\
\hline 7 & General Mills & 21 & Coscto & 34 & AT\&T & 47 & Bank of America \\
\hline 9 & 3M Company & 22 & Hewlett-Packard & 35 & American Express & 48 & Comcast \\
\hline 10 & Toyota & 23 & Target Corp & 36 & Walmart & 49 & J. P. Morgan \\
\hline 11 & Berkshire Hathaway & 24 & Home Depot & 37 & Starbucks & 50 & Wachovia \\
\hline 12 & Proctor and Gamble & 25 & Dell & 38 & State Farm Ins. & & \\
\hline 13 & Walt Disney & 26 & General Electric & 39 & Royal DutchShell & & \\
\hline
\end{tabular}

APPENDIX E

Top 50 for Newsweek's Green Rankings

\begin{tabular}{|c|c|c|c|c|c|c|c|}
\hline Rank & Company Names & Rank & Company Names & Rank & Company Names & Rank & Company Names \\
\hline 1 & Hewlett-Packard & 14 & Sun Microsystems & 27 & Estee Lauder & 40 & $3 \mathrm{M}$ \\
\hline 2 & Dell & 15 & Sprint Nextel & 28 & Xerox & 41 & JPMorgan Chase \\
\hline 3 & $\mathrm{~J} \& \mathrm{~J}$ & 16 & Adobe Systems & 29 & American Express & 42 & Marriott International \\
\hline 4 & Intel & 17 & Advanced Micro Devices & 30 & ITT & 43 & Eaton \\
\hline 5 & IBM & 18 & Kohl's & 31 & Microsoft & 44 & J. C. Penney \\
\hline 6 & State Street & 19 & Allegran & 32 & Travelers & 45 & CB Richard Ellis Group \\
\hline 7 & Nike & 20 & Staples & 33 & United Technology & 46 & Starwood Hotels \& Resorts \\
\hline 8 & Bristol-Myers Squibb & 21 & Motorola & 34 & Walt Disney & 47 & Pall \\
\hline 9 & Applied Materials & 22 & McDonald's & 35 & Baxter International & 48 & First Solar \\
\hline 10 & Starbucks & 23 & Texas Instrument & 36 & Coca-Cola & 49 & Virgin Media \\
\hline 11 & Johnson Controls & 24 & Citigroup & 37 & Agilent Tech. & 50 & Macy's \\
\hline 12 & Cisco Systems & 25 & Avon Products & 38 & Gap & & \\
\hline 13 & Wells Fargo & 26 & Proctor \& Gamble & 39 & Colgate-Palmolive & & \\
\hline
\end{tabular}


APPENDIX F

The Seven Companies Shared by all Four Lists and the Rankings for Each

\begin{tabular}{|c|c|c|c|c|}
\hline Company & CSRI Rankings & Reputations & Newsweek & Fortune \\
\hline Walt Disney & 4 & 13 & 34 & 13 \\
\hline Microsoft & 10 & 7 & 31 & 10 \\
\hline Johnson and Johnson & 3 & 1 & 3 & 5 \\
\hline IBM & 30 & 27 & 5 & 17 \\
\hline Hewlett Packard & 38 & 22 & 1 & 30 \\
\hline Coca Cola Company & 31 & 4 & 36 & 12 \\
\hline $3 \mathrm{M}$ & 12 & 9 & 40 & 18 \\
\hline
\end{tabular}

